\title{
Pemanfaatan Aplikasi Virtusee Dalam Pemetaan Prasarana Transportasi Berbasis GIS Di Wilayah UPT Surabaya
}

\author{
Putu Gde Ariastita1, Pande K Yokarmana2 \\ 1Jurusan Perencanaan Wilayah dan Kota, Fakultas Teknik Sipil dan Perencanaan, Institut Teknologi Sepuluh \\ Nopember (ITS), Surabaya 60111 Indonesia \\ 2PT. Inosoft Trans Sistem \\ ariastita@gmail.com
}

\begin{abstract}
Abstrak
Tulisan ini disusun dari hasil kajian pemetaan prasarana transportasi berbasis GIS di wilayah UPT Surabaya, Jawa Timur. Langkah awal dalam pemetaan adalah identifikasi prasarana transportasi. Pemetaan ini penting, untuk mengetahui kondisi dan karakteristik prasarana saat ini, sehingga nantinya dapat dijadikan sebagai dasar perencanaan dan pengambilan keputusan pengembangannya di masa mendatang. Adapun tujuan dari tulisan ini adalah menjelaskan proses penyusunan data base dari hasil identifikasi prasarana transportasi di UPT LLAJ Surabaya. Proses penyusunan data base dari hasil identifikasi prasarana transportasi merupakan kegiatan yang kompleks, mengingat prasarana transportasi relatif beraneka ragam, baik di matra darat, laut, dan udara. Keberagaman ini tentunya memerlukan teknik yang khusus, sehingga proses identifikasinya berjalan dengan efisien dan efektif. Untuk itu, dalam proses identifikasi ini digunakan aplikasi virtusee yang kemudian diintegrasikan dengan Geographic Information System (GIS), untuk menghasilkan data base prasarana transportasi. Hasil kajian menunjukkan, aplikasi virtusee dapat mendukung proses identifikasi prasarana transportasi dengan baik. Hal ini ditunjukkan dengan memberikan kemudahan bagi surveyor dalam menginput data secara paperless, real time, terintegrasi dengan map, dan termonitor oleh kordinator. Data yang masuk secara real time memudahkan untuk koreksi, sehingga bilamana terjadi kesalahan, bisa segera diperbaiki di lapangan. Proses kompilasi dan analisis dapat juga dilakukan secara paralel dengan survey, sehingga dapat mempercepat pelaporan. Pada akhirnya output data base prasarana transportasi dapat tersusun dengan valid dan visual yang manarik serta mudah dipahami.
\end{abstract}

Kata kunci: Prasarana Transportasi, GIS, Virtusee

\section{PENDAhUluan}

Prasarana transportasi adalah bangunan maupun penanda yang diperlukan untuk memberikan pelayanan atau jasa bagi pengguna transportasi. Prasarana transportasi terdapat pada bidang transportasi darat, laut, dan udara. Pada transportasi darat di bidang lalu lintas meliputi prasarana terminal penumpang, perlengkapan jalan, jalan raya, jembatan timbang, pengujian kendaraan bermotor, terminal cargo, dan rest area. Di bidang perkeretaapian meliputi stasiun kereta api, dry port, perlintasan sebidang, Alarm Early Warning System (AEWS). Prasarana pada transportasi laut meliputi pelabuhan penyeberangan/dermaga dan sarana bantu navigasi pelayaran. Sementara itu, di udara meliputi bandar udara, helipad, dan sarana bantu navigasi penerbangan.

Jenis-jenis prasarana transportasi relatif banyak dan beragam. Pemerintah Provinsi Jawa Timur relatif kesulitan dalam merencanakan, mengadakan, memelihara, maupun mengendalikannya. Langkah awal yang perlu dilakukan untuk mengelola prasarana transportasi adalah menyusun data basenya. Penyusunan data base ternyata juga mengalami kendala karena luasnya lingkup dan komponen dari prasarana transportasi. Secara lebih spesifik, proses mendata prasarana transportasi tidaklah mudah, sehingga memang diperlukan mekanisme yang efektif dan efisien dalam mengindentifikasinya. Salah satu pendekatan yang dilakukan adalah melalui identifikasi online dan real time, untuk mempecepat proses koleksi data pada data base yang berbasis spatial.

Pada tahap akhir data base spatial dibutuhkan Geographic Information System (GIS) sebagai sarana mengkompilasi data secara terintegrasi dengan persebaran spatial. Sistem Informasi Geografi dapat menggabungkan data numerik dan spatial. Langkah sebelum mengkompilasi data di dalam GIS adalah mengidentifikasi prasarana transportasi. Proses identifikasi ini perlu dilakukan secara real time dan online dalam rangka efesiensi input data. Untuk mendukung hal tersebut digunakan aplikasi Virtusee. Aplikasi ini juga dapat diintegrasikan dengan GIS. Tulisan ini membahas proses 
identifikasi objek melalui aplikasi Virtusee yang kemudian diintegrasikan ke dalam GIS untuk menjadi data base prasarana transportasi di Jawa Timur.

Tulisan ini merupakan pembahasan terhadap kajian Penyusunan Identifikasi Prasarana Transportasi Berbasis GIS Di UPT LLAJ Surabaya yang diselenggarakan Tahun 2015. Wilayah UPT Surabaya terdiri dari tiga Kabupaten/kota yakni Kota Surabaya, Kabupaten Gresik dan Kabupaten Sidoarjo.

\section{TINJAUAN PUSTAKA}

\subsection{Sistem Informasi Geografis}

Sistem Informasi Geografis (SIG) adalah sistem yang berbasis komputer yang digunakan untuk menyimpan dan memanipulasi informasi-informasi geografi. SIG dirancang untuk mengumpulkan, menyimpan, dan menganalisis objekobjek dan fenomena karena lokasi geografi merupakan karakteristik yang penting atau-kritis untuk dianalisis. Oleh karena itu, SIG merupakan sistem komputer yang memiliki empat kemampuan dalam menangani data yang bereferensi geografi, yaitu masukan, manajemen data (penyimpanan dan pemanggilan data), analisis dan manipulasi cara, serta keluaran.

Karena merupakan suatu sistem, informasi geografis terdiri dari 4 subsistem pokok, yaitu:

a. Subsistem Masukan

Fungsi dari subsistem ini adalah mengumpulkan dan mempersiapkan data spasial dan atribut dari berbagai s umber. Selain itu, subsistem ini bertanggung jawab dalam melakukan konversi atau melakukan transformasi formal. Data data asli ke dalam format yang dapat digunakan oleh SIG.

b. Subsistem Penyimpanan

Fungsi dari subsistem ini adalah mengorganisasikan data, baik data spasial maupun data atribut ke dalam basis data (bank data). Penyimpanan dengan cara demikian mempermudah dalam pemanggilan, pengeditan dan pembaharuan data.

c. Subsistem Pengolahan dan Pengkajian

Fungsi dari subsistem ini adalah menentukan informasi -informasi yang dapat dihasilkan oleh SIG. Selain itu, subsistem ini juga melakukan pengolahan dan pemodelan data untuk menghasilkan informasi yang diharapkan.

d. Subsistem Penyajian

Fungsi dari subsistem ini adalah menampilkan data dan hasil dari pengolahannya, baik sebagian maupun seluruhnya. Data dan hasil pengolahannya tersebut ditampilkan antara lain dalam bentuk tabel, grafik, dan peta (khususnya para digital).

Data spasial merupakan data yang paling penting dalam SIG. Data spasial mempunyai pengertian sebagai suatu data yang mengacu pada posisi, obyek, dan hubungan diantaranya dalam ruang bumi. Data spasial merupakan salah satu komponen dari informasi, dimana didalamnya terdapat informasi mengenai bumi termasuk permukaan bumi, di bawah permukaan bumi, perairan, kelautan dan bawah atmosfer. Data spasial dan informasi turunannya digunakan untuk menentukan posisi dari identifikasi suatu elemen di permukaan bumi.

Alasan GIS dibutuhkan adalah karena untuk data spatial penanganannya sangat sulit terutama karena peta dan data statistik cepat kadaluarsa sehingga tidak ada pelayanan penyediaan data dan informasi yang diberikan menjadi tidak akurat. Ada dua keistimewaan analisa melalui Geographical Information System (GIS) yakni:

- Analisa Proximity

Analisa Proximity merupakan suatu geografi yang berbasis pada jarak antar layer. Dalam analisis proximity GIS menggunakan proses yang disebut dengan buffering (membangun lapisan pendukung sekitar layer dalam jarak tertentu untuk menentukan dekatnya hubungan antara sifat bagian yang ada).

- Analisa overlay

Proses integrasi data dari lapisan-lapisan layer yang berbeda disebut dengan overlay. Secara analisa membutuhkan lebih dari satu layer yang akan ditumpang susun secara fisik agar bisa dianalisa secara visual.

Tabel 1. Kelebihan-Kelebihan Sistem Informasi Geografis

\begin{tabular}{|l|l|l|}
\hline Peta & SIG & Manual \\
\hline Penyimpanan & Database digital baku dan terpadu & Skala dan standar berbeda \\
\hline Pemanggilan Kembali & Pencatatan dengan komputer & Cek manual \\
\hline Pemutakhiran & Sistematis & Mahal dan memakan waktu \\
\hline Analisis Overlay & Cepat & Memakan waktu dan tenaga \\
\hline Penayangan & Murah dan cepat & Mahal \\
\hline
\end{tabular}

\subsection{Aplikasi Virtusee Sebagai Subsistem Masukkan dalam GIS}

Aplikasi virtusee merupakan alat yang berupa software yang ada di smartphone berbasis operating system (OS) Android v2 ke atas. Aplikasi ini pada dasarnya mengoptimalkan penggunaan fitur global positioning system (GPS) dan kamera yang ada pada masing-masing smartphone. Dengan demikian smartphone untuk mendukung aplikasi ini harus 
memiliki fitur GPS dan kamera. Prinsip kerja aplikasi ini hampir sama dengan geotagging pada smartphone yaitu pengambilan gambar yang memiliki informasi geografis sehingga lokasi pengambilan gambar dapat muncul pada peta geografis. Meskipun demikian aplikasi ini memiliki keunggulan adanya form isian informasi kondisi lainnya dari tempat yang disimpan. Isian form tersebut dapat disesuaikan dengan kebutuhan survey. Dengan demikian foto yang diunggah pada server selain memiliki informasi geografis juga memiliki informasi lainnya seperti kondisi lokasi, masalah, bentuk dan lainnya. Aplikasi Virtusee memiliki dua unsur utama yaitu tampilan pada smartphone dan server data. Aplikasi pada smartphone merupakan portal yang berfungsi upload data oleh masing-masing surveyor, sedangkan server data merupakan portal yang menghimpun keseluruhan hasil survey dalam satu tempat dan dapat dilihat secara online. Server data aplikasi ini diakses melalui www.virtusee.com. Kedua unsur aplikasi ini dapat diakses dengan login terlebih dahulu. Tampilantampiran Aplikasi Virtusee diperlihatkan pada Gambar berikut.

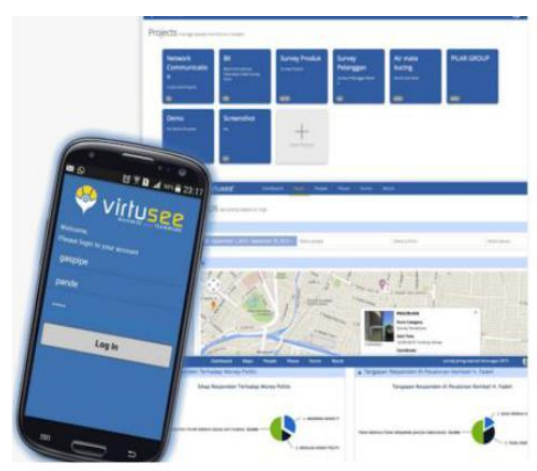

Gambar 1. Tampilan Aplikasi Virtusee

Sumber: http://www.virtusee.com/example.html

Aplikasi ini tidak dapat berdiri sendiri dan memerlukan dukungan dari operasi aplikasi android lainnya. Aplikasiaplikasi yang mendukung virtusee harus berjalan beriringan. Salah satunya adalah aplikasi GPS Test. Aplikasi ini membantu saving data pada aplikasi virtusee sudah memiliki kordinat lokasi yang lebih akurat yang tidak dapat ditampilkan oleh virtusee sendiri.

Tabel 2 Aplikasi Pendukung Virtusee

\begin{tabular}{|l|l|l|l|}
\hline No. & Nama Aplikasi & $\begin{array}{l}\text { Tampilan } \\
\text { Icon }\end{array}$ & Fungsi Pembantu Pada Virtusee \\
\hline 1. & GPS Test & 6 & $\begin{array}{l}\text { Membantu mengetahui keakuratan pengambilan kordinat lokasi obyek survey } \\
\text { sebelum disimpan pada server. }\end{array}$ \\
\hline 2. & Google Maps & - & $\begin{array}{l}\text { - Membantu mengetahui aktif tidaknya GPS smartphone } \\
\text { - Kalibrasi GPS }\end{array}$ \\
\hline 3. & Browser & - Mengetahui lokasi pada peta \\
\hline
\end{tabular}

\section{METODE}

\subsection{Metode Pengumpulan Data}

Pengumpulan data dilakukan dengan dua metode yaitu survey primer dan survey sekunder. Metode survey primer dilakukan untuk memperoleh data secara langsung dari sumber data lapangan dari obyek yang disurvey. Sementara, metode survey sekunder dilakukan untuk memperoleh data secara tidak langsung dari sumber data seperti instansi pemerintah maupun instansi lainnya. Pada kegiatan ini lebih banyak dilakukan pendataan data primer baik dokumen foto prasarana transportasi maupun kondisi obyek survey. Khusus pada survey primer, kegiatan observasi dan kuisioner diintegrasikan dalam sebuah sistem berbasis android yaitu Virtusee. Gambar 2 merupakan system integrasi aplikasi Virtusee untuk mendukung survey lapangan. Hasil survey lapangan yang terintegrasi dengan server data mempermudah mengidentifikasi lokasi obyek-obyek prasarana transportasi yang damati. Selain itu data karakteristik, kondisi, potensi dan masalah dari obyek yang diamati akan langsung terkumpul dan tersimpan dalam server sehingga pengolahan database dapat dilakukan dengan cepat. 

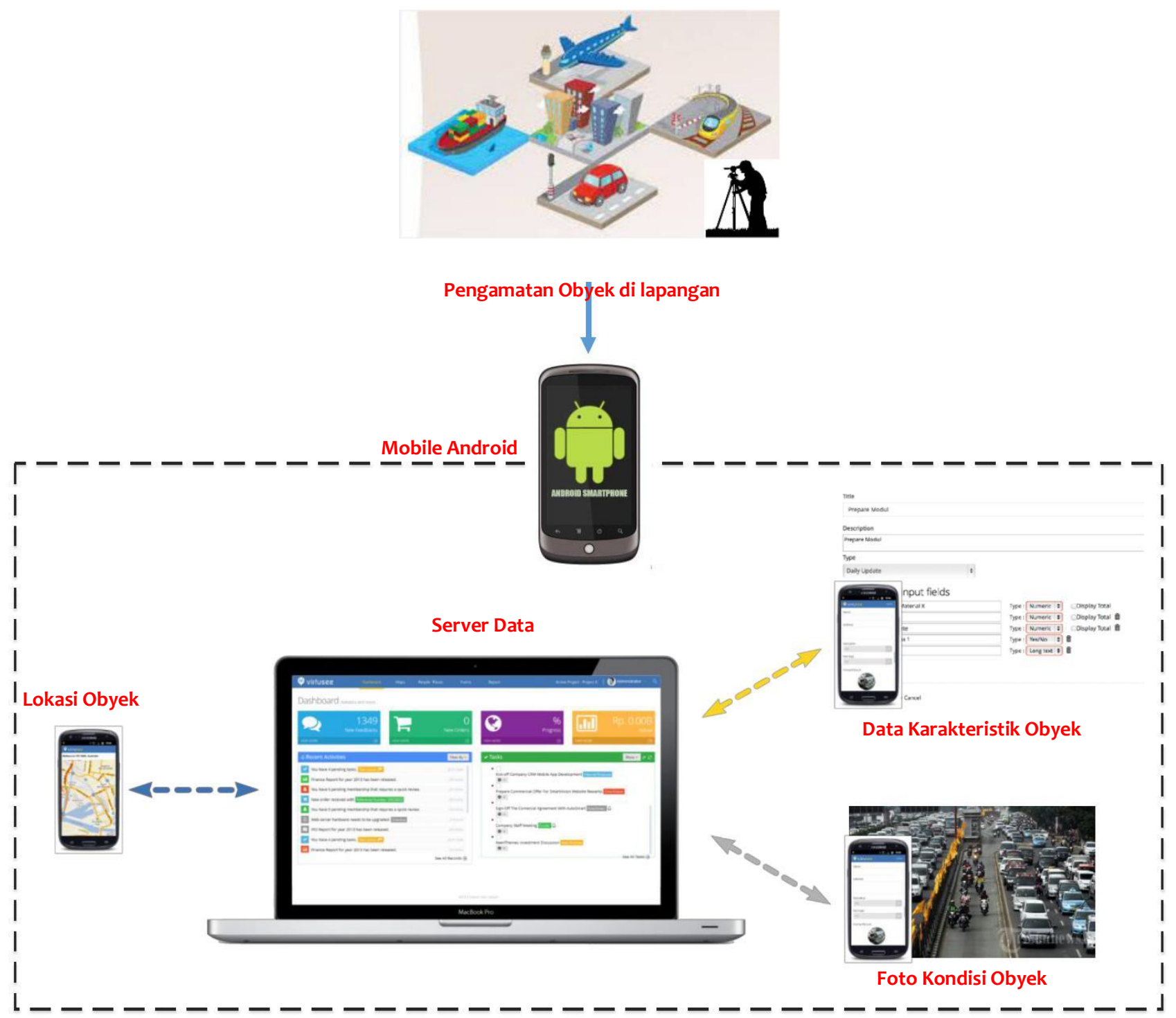

Gambar 2. Integrasi Data Survey Melalui Virtusee

\subsection{Metode Penyusunan Prasarana Transportasi Berbasis Sistem Informasi Geografis}

Tahapan-tahapan dalam penyusunan Sistem Informasi Geografis dari dalam kegiatan ini adalah sebagai berikut:

1. Menyiapkan peta geografis Jawa Timur beserta jaringan jalan dengan membedakan masing-masing potongan ruas jalan yang diamati/disurvey.

2. Mengunduh data lokasi dan data karakteristik masing-masing prasarana transportasi yang sudah disurvey dari server Virtusee.

3. Melakukan update peta dengan melakukan digitasi point pada titik-titik lokasi prasarana tarnsportasi.

4. Melakukan update peta geografis dengan melakukan digitasi area (polygon) pada lokasi prasarana tarnsportasi yang berbasis area.

5. Memberikan identitas pada masing-masing prasarana pada peta geografis.

6. Melakukan tabulasi data karakteristik, kondisi, masalah dan gambar masing-masing prasarana transportasi yang telah disurvey berdasarkan identitas prasarana transportasi pada peta geografis.

7. Mengintegrasikan data tabulasi dengan data lokasi pada peta geografis.

\section{HASIL DAN PEMBAHASAN}

Gambar-gambar berikut merupakan data base prasarana transportasi di wilayah UPT Surabaya, baik di bidang transportasi darat, laut, dan udara. Visualisasi gambar data base berikut merupakan hasil dari proses integrasi antara GIS dan sistem inputnya dengan menggunakan aplikasi Virtusee. 




Gambar 4 Data Base Halte dan Rambu

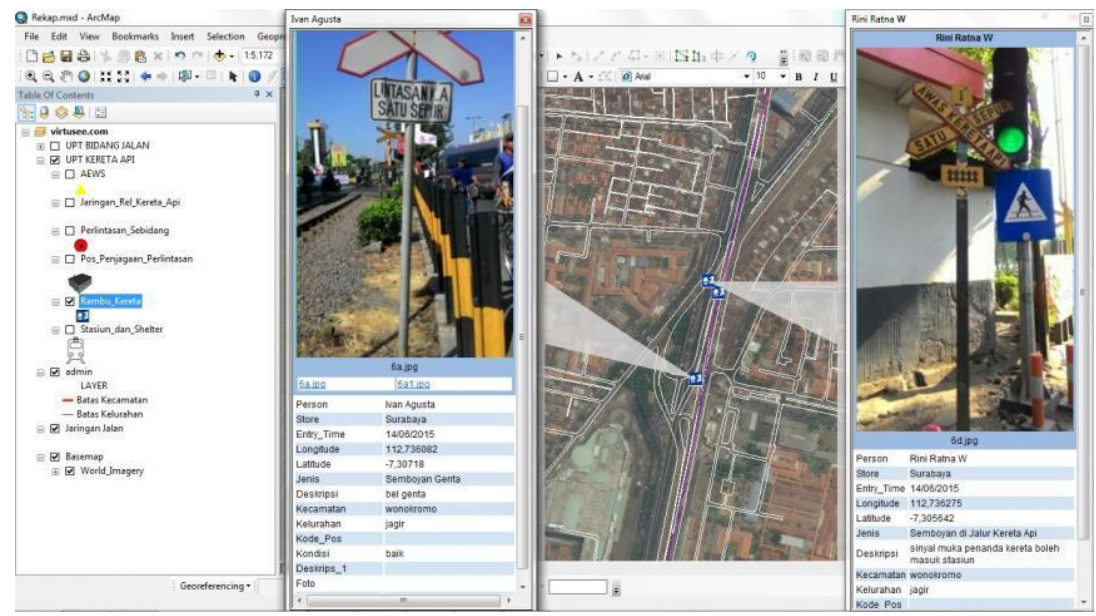

Gambar 5 Data Base Rel dan Rambu

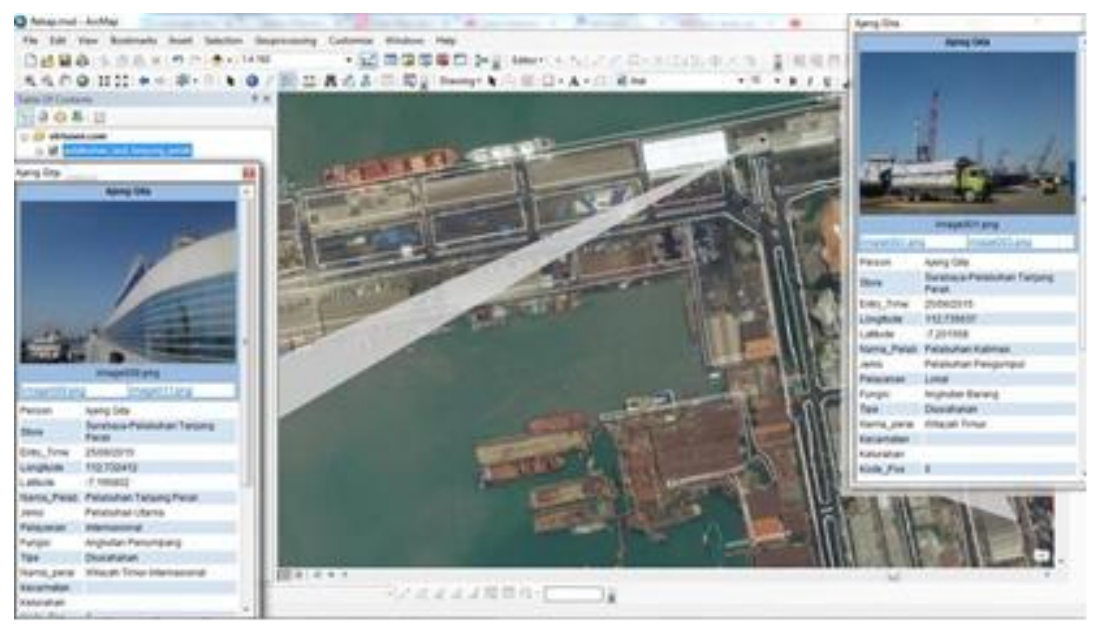

Gambar 6 Data Base Pelabuhan 


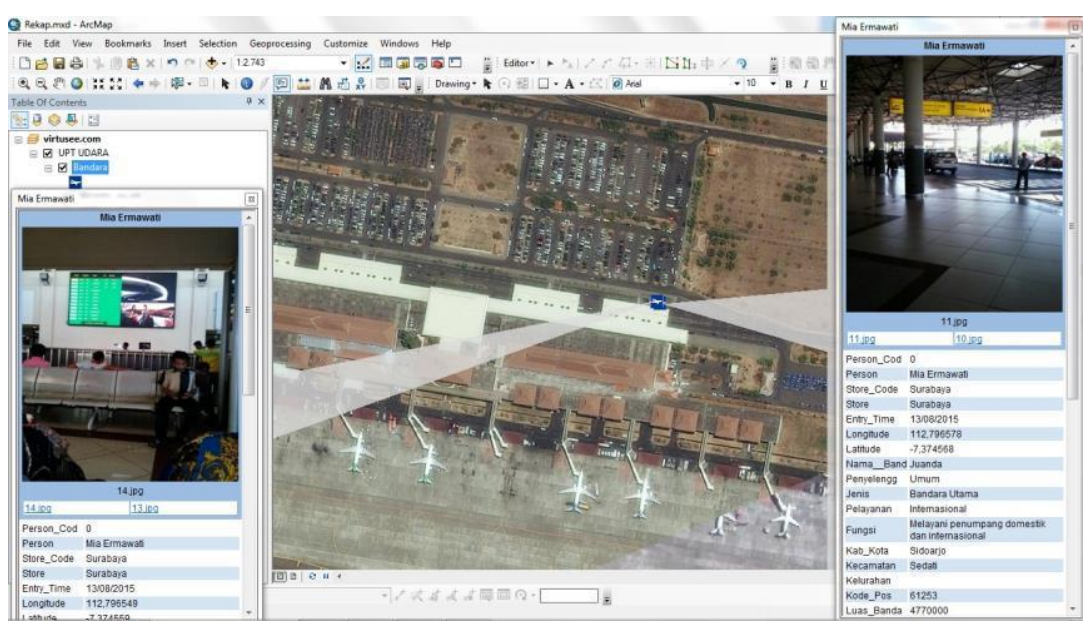

Gambar 7 Data Base Bandara

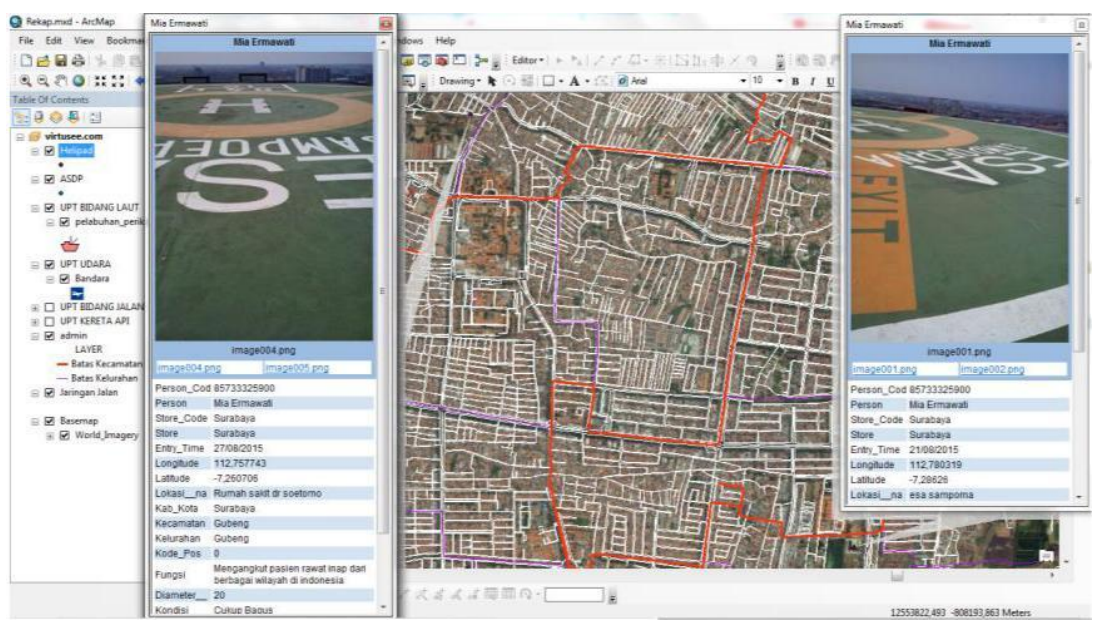

Gambar 8 Data Base Helipad

Gambar 4 sampai 8 memperlihatkan cuplikan-cuplikan hasil akhir data base prasarana transportasi di UPT Surabaya. Pada gambar tersebut terlihat objek-objek prasarana yang dapat teridentifikasi dengan baik. Yang dimaksud teridentifikasi baik adalah posisi objek sesuai dengan kondisi di lapangan, tervisualisasi dengan jelas pada gambaran spasial. Hal lain adalah diskripsi yang lengkap dan dapat terintegrasi dengan objek prasarana secara spasial. Deskripsi objek juga dilengkapi dengan foto, sehingga dapat tergambarkan kondisi prasarana transportasinya. Indikator-indikator yang telah dijelaskan sebelumnya menunjukkan bahwa data base yang telah disusun telah sesuai dengan kebutuhan sebagai inisiasi awal sebuah sistem informasi.

Hasil yang dicapai ini merupakan proses integrasi antara aplikasi Virtusee dengan GIS. Aplikasi Virtusee sangat berperan dalam proses input data, dimana kebutuhan data numerik, deskriptif, visual, dan spatial dapat diakomodasi. Tentu saja dari input ini selanjutnya memudahkan dalam proses kompilasinya melalui GIS. Untuk selanjutnya ditunjukkan secara visual seperti yang diperlihatkan pada Gambar.

Walaupun Aplikasi Virtusee dapat berperan dengan baik dalam pelaksanaan kegiatan ini, namun terdapat beberapa kendala yang ditemui dalam pelaksanaan survey primer. Kendala tersebut diantaranya, masalah blank spot, dimana pada daerah-daerah tertentu yang tidak ada sinyal, proses input dalam melalui Virtusee tidak dapat dilakukan. Kendala ini diatasi dengan melakukan identifikasi secara offline. Hal lain yang menjadi kendala adalah dalam penentuan kordinat objek prasarana transport masih membutuhkan waktu yang relatif lama. Kendala ini masih menjadi bahan perbaikan dari aplikasi Virtusee.

Dalam pelaksanaan penyusunan data base prasarana transportasi ini, tantangan berikutnya adalah proses updating data di masa mendatang. Perlu dipikirkan mekanisme updating yang harus dilakukan, yang tentu saja mempertimbangkan aspek efektifitas dan efisiensinya. Saat ini proses identifikasi objek dilakukan dengan mekanisme survey, dimasa mendatang, kiranya perlu dipikirkan mekanisme updating yang bersifat outunomous. Hal lain yang perlu dipertimbangkan juga pada tahap berikutnya adalah transformasi data base ini menjadi sistem pengambilan keputusan atau menjadi bagian di dalam proses perencanaan, pembangunan, dan pemeliharaan prasarana transportasi. 


\section{KESIMPULAN DAN REKOMENDASI}

Kesimpulan yang dapat diambil dari pembahasan ini adalah aplikasi Vertusee ternyata dapat berperan dengan efektif dan efisien dalam proses identifikasi objek prasarana transportasi di wilayah UPT Surabaya. Aplikasi Virtusee dapat menjadi instrumen survey yang selanjutnya terintegrasi dengan subsistem masukkan dalam GIS. Dengan demikian, dalam proses kompilasi data dengan GIS melalui software ArcGIS dapat dilakukan dengan mudah dan cepat. Data base yang dihasilkan sudah menunjukkan presisi objek disertai dengan deskripsi yang lengkap dari objek prasarana transportasi yang sesuai dengan kebutuhannya.

Rekomendasi yang dapat diberikan sehubungan dengan pengembangan baik data base yang dihasilkan maupun aplikasi Virtusee adalah sebagai berikut:

- Pengembangan pada aplikasi Virtusee berupa mempercepat proses penentuan kordinat objek, pengembangan sistem mitigasi pada area blank spot, serta pengembangan fitur-fitur yang memungkinkan data dapat terkoleksi secara outonomous

- Pada data base yang telah dihasilkan perlu dikembangkan mekanisme updating yang efektif dan efisien serta dikembangkan menjadi sistem pengambilan keputusan maupun perencanaan.

\section{DAFTAR PUSTAKA}

Use the "Insert Citation" button to add citations to this document. 